\title{
MECHANICAL PROPERTIES OF CITRUS AND IMPACT DAMAGE UNDER DIFFERENT STORAGE CONDITIONS
}

\author{
C. Ortiz, A. Torregrosa
}

\begin{abstract}
Mechanical handling of fresh-market citrus is restricted by damage susceptibility. The objective of this research study was to determine the effect of variety and storage conditions on the resistance of citrus to impact damage. Three citrus varieties, two of them in two different stages of maturity, were tested in two different experiments: a freedropping experiment and a physical properties experiment. Two relative humidity conditions and two temperature conditions were studied. In the physical properties test, puncture resistance and compression resistance were measured. Significant differences were found in the damage resistance of each of the varieties. Puncture resistance of the peel of postharvest citrus and whole-fruit compression resistance are related to storage temperature and relative humidity conditions. To increase citrus whole-fruit compression resistance and peel puncture resistance, low temperatures and high relative humidity should be used. Under suitable previous temperature and relative humidity conditions, citrus varieties such as 'Valencia Late,' with a high resistance to compression and low peel deformation, could be apt for aggressive mechanical handling.
\end{abstract}

Keywords. Citrus fruits, Damage, Mechanical handling, Mechanical properties, Relative humidity, Temperature.

$\mathrm{T}$ The exact amount of perishable food crops produced in the world that are lost after harvest is not known, although figures ranging from $1 \%$ to $50 \%$ have been mentioned (Yahia et al., 2004; Kader, 2005). Mechanical damage represents a serious hazard to quality and has the potential to significantly reduce the value of the product (Van Zeebroeck et al., 2007). Mechanical damage to fruit is mainly caused by impacts during harvest, transport, and handling because these forces are higher in incidence and magnitude than static forces. Citrus fruit postharvest processing involves a large number of mechanical operations associated with mechanical damage due to dynamic loads, mainly impacts (Mohsenin, 1986; Bielza et al., 2003). However, static forces, such as compression loads during postharvest handling and storage, can also cause important damage to fruit (Bollen et al., 2001). Furthermore, other damage such as abrasion (Ericsson and Tahir, 1996), puncture, and prolonged vibration during transport (Armstrong et al., 1991) may also be produced.

Mechanical damage to fruit has two immediate consequences: the appearance of bruises, which reduce the commercial value of the fruit, and peel wounds, which may lead to further infections by pathogens (García-Ramos et al., 2004). According to Tuset (1987), in a typical season, the percentage of rotting fruit after harvesting is between $3 \%$ and 6\%. In Spain, citrus production is mainly destined for

Submitted for review in October 2013 as manuscript number FPE 10479; approved for publication by the Food \& Process Engineering Institute of ASABE in February 2014.

The authors are Coral Ortiz, Associate Professor, and Antonio Torregrosa, Professor, Department of Rural and Agri-food Engineering, Polytechnic University of Valencia, Spain. Corresponding author: Coral Ortiz, Camino de Vera s/n, 46022 Valencia, Spain; phone: 0034-963877000, ext. 72951; email: cortiz@dmta.upv.es. fresh consumption (Torregrosa et al., 2009); consequently, most consumers associate quality with a good appearance and the total absence of external defects (Blasco et al., 2007).

According to Bollen et al. (2001), the most useful measure that commercial operators can use to assess fruit damage is the proportion of a product line that will sustain damage of economic importance. Various authors have used fruit free-dropping tests in the laboratory to assess the susceptibility of fruit to bruising (Pang et al., 1996; Timm and Guyer, 1998; Lu and Wang, 2007; Scherrer Montero et al., 2009; Ortiz et al., 2011). According to Pang et al. (1996), the dropping test required 20 fruits per sample.

The physical properties of fruit provide important information for predicting product behavior during mechanical handling (Arazuri et al., 2007). The correlation between laboratory test variables and fruit quality will contribute to the development of an optimal solution for mechanization. However, it is not easy to determine the correct relationship between physical property variables and internal tissue processes. Hertog et al. (2004) studied the firmness of tomato using both invasive techniques (such as the destructive puncture test) and non-invasive techniques (such as acoustic firmness) and indicated that firmness evolved differently over storage time depending on the measurement technique applied. The same authors also stressed the complexity of evaluating an internal tissue process by measuring physical properties.

In many experiments, the maximum force in a puncture compression test is considered to be the resistance of the fruit peel, and the force-deformation ratio with a disk in a whole-fruit compression test is considered to be the wholefruit resistance.

Churchill et al. (1980) used three different physical 
properties to assess orange damage susceptibility during mechanical harvesting. Material testing equipment was used to measure puncture resistance, burst resistance, and peel tensile resistance. The puncture test (with a $0.0064 \mathrm{~m}$ diameter rod) was used to simulate the forces encountered when fruit comes into contact with small branches. Juste et al. (1988) used a puncture test to assess the physical properties of citrus fruit in order to determine the limits of safe handling during mechanical harvesting. Menesatti et al. (2005) found that mandarins presented less firmness and elasticity than oranges and lemons, with significant differences found between varieties. Flood et al. (2006) studied the physical properties of oranges using puncture and burst tests, and a model was developed that related punch diameter to puncture force.

From studies conducted on other products, it has been proven that, apart from the structural cell wall components, cell turgor also contributes to firmness. According to Lin and Pitt (1986), increased turgor makes the cell fail at a lower load in compression tests. In assessing the factors that influence the mechanical properties and bruise susceptibility of apples and pears, García et al. (1995) showed that fruit turgidity (deformation such as skin puncture) and Magness-Taylor firmness influenced bruise susceptibility (measured as bruise volume). Fruits exposed to different relative humidity conditions over the $16 \mathrm{~h}$ preceding the test showed significant differences in their physical properties and bruise susceptibility. Deformation such as skin puncture was the physical parameter that was most strongly related to fruit turgidity. Fruits stored in high relative humidity conditions presented higher skin puncture deformation (higher turgidity) and were more susceptible to bruising. Turgidity and firmness influence bruise susceptibility independently, and their effects are combined during the ripening of apples and pears.

Sigh and Reddy (2006) studied the physico-mechanical properties of Nagpur mandarins by performing peel tensile, peel cutting, fruit compression, puncture resistance, and fruit cutting tests. In the puncture resistance test, the probe speed was $0.001 \mathrm{~m} \mathrm{~s}^{-1}$. In the compression test, the force was applied at a speed of $0.001 \mathrm{~m} \mathrm{~s}^{-1}$ to compress the fruit for $0.01 \mathrm{~m}$ from the contact point and was considered to be firmness. In the compression test, firmness slowly decreased during postharvest storage for both environmental and refrigerated conditions. In the puncture test, the rupture force (maximum force) was observed to be higher in oranges stored in refrigerated conditions than those kept in environmental conditions.

It is important to assess the mechanical properties of fresh market citrus that make the fruits acceptable to con- sumers and resistant to mechanical handling. Additionally, another key aspect is to understand the relationship between storage temperature and relative humidity conditions and damage susceptibility. The objective of this research study was to evaluate the effect of variety and storage conditions (temperature and relative humidity) on the mechanical properties and mechanical damage of citrus.

\section{Materials AND Methods}

Three varieties of citrus from different orchards in the Valencia region were tested, with two of them in two different stages of ripeness: 'Valencia Late,' 'Valencia Late' overripe, 'Orogrande,' 'Marisol,' and 'Marisol' overripe (table 1). Fruit samples were carefully hand-harvested, leaving the calyx attached to the fruit, and transported to the laboratory. All the varieties, except the overripe samples, were harvested at the commercial harvesting stage. Four sets of fruit were stored for $48 \mathrm{~h}$ before the test at two different temperature conditions (cold refrigerated chamber at $4^{\circ} \mathrm{C}$ to $7^{\circ} \mathrm{C}$ and environmental at $16^{\circ} \mathrm{C}$ to $25^{\circ} \mathrm{C}$ ) and two different relative humidity conditions: high (80\% to $95 \%)$ and medium (50\% to $80 \%$ ).

Two experiments were carried out: a free-dropping experiment (30 fruits per sample) and a mechanical properties experiment (ten fruits per sample). In the free-dropping experiment, individual fruits were dropped over an empty polyethylene harvesting box from a height of $2 \mathrm{~m}$. The percentage of damaged fruits after two weeks of storage was registered as the damage percentage (\%).

In the mechanical properties experiment, five fruits were used per test, and three repetitions were performed per fruit. Two tests were carried out: $10 \mathrm{~mm}$ compression of the whole fruit with a disk (20 mm diameter and $3 \mathrm{~mm}$ height) and peel puncture with a cylindrical rod $(1.5 \mathrm{~mm}$ diameter). The maximum deformation required to puncture the fruit surface from the force-deformation curve was registered as the maximum puncture deformation (mm) (fig. 1). Higher peel puncture deformation is related to lower resistance to peel puncture.

The force-deformation ratio from the whole-fruit compression force-deformation curve was registered as the compression resistance $\left(\mathrm{N} \mathrm{mm}^{-1}\right)$ (fig. 1). A universal testing machine (Ibertest, Madrid, Spain, www.ibertestint.com) with a digital dynamometer (Centormeter, Andilog Technologies, Vitrolles, France, www.andilog.com, 0 to $500 \mathrm{~N}$, $0.1 \%$ precision, $1000 \mathrm{~Hz}$ sampling frequency, and 1/10,000 FS resolution) were used. In both tests, the fruit was placed on a piece of modeling clay, and steps were taken to ensure

Table 1. Mean weight (and standard deviation), maturity index, damage percentage, maximum puncture deformation, and compression resistance for each variety. ${ }^{[a]}$

\begin{tabular}{|c|c|c|c|c|c|}
\hline Variety & $\begin{array}{l}\text { Mean } \\
\text { Weight } \\
\text { (g) }\end{array}$ & $\begin{array}{c}\text { Mean } \\
\text { Maturity Index } \\
\left(10 \times{ }^{\circ} \text { Brix g }^{-1} \mathrm{~L}^{-1}\right)\end{array}$ & $\begin{array}{l}\text { Mean Damage } \\
\text { Percentage } \\
(\%)\end{array}$ & $\begin{array}{c}\text { Mean Maximum } \\
\text { Puncture Deformation } \\
(\mathrm{mm})\end{array}$ & $\begin{array}{c}\text { Mean Compression } \\
\text { Resistance } \\
\left(\mathrm{N} \mathrm{mm}^{-1}\right)\end{array}$ \\
\hline 'Valencia Late' & $156.4 \pm 29.7$ & 6.8 & $0.0 \mathrm{a}$ & $1.50 \mathrm{a}$ & $1.75 \mathrm{a}$ \\
\hline 'Marisol’' & $96.7 \pm 21.4$ & 6.9 & $6.0 \mathrm{ab}$ & $1.81 \mathrm{~b}$ & $2.51 \mathrm{~b}$ \\
\hline 'Orogrande' & $102.7 \pm 34.4$ & 16.1 & $8.0 \mathrm{ab}$ & $3.28 \mathrm{c}$ & $3.75 \mathrm{c}$ \\
\hline 'Valencia Late' overripe & $196.4 \pm 44.9$ & 6.9 & $8.3 \mathrm{ab}$ & $4.03 \mathrm{~d}$ & $5.45 \mathrm{~d}$ \\
\hline 'Marisol' overripe & $146.0 \pm 21.0$ & 9.0 & $22.5 \mathrm{c}$ & $5.93 \mathrm{e}$ & $6.10 \mathrm{e}$ \\
\hline
\end{tabular}

[a] Within a column, means followed by the same letter are not significantly different at the $95 \%$ confidence level (according to the Duncan test). 

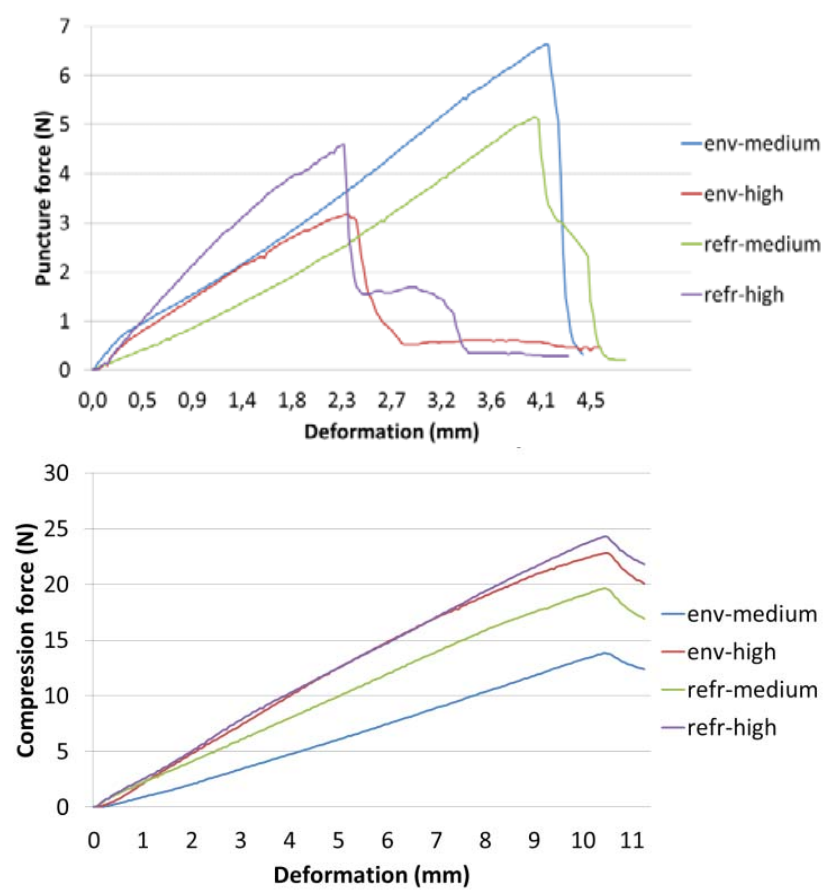

Figure 1. Force deformation puncture curves (top) and force deformation compression curves (bottom) of 'Marisol' mandarins according to temperature $($ env $=$ environmental, refr $=$ refrigerated $)$ and relative humidity (medium and high).

that the stem-calyx axis was lying orthogonal to the rod. The tests were carried out at a probe speed of $1 \mathrm{~mm} \mathrm{~s}^{-1}$.

Data analysis was performed by analysis of variance and Duncan's multiple range test to separate means using Statgraphics Plus 5.0 (Statpoint Technologies, Warrenton, Va.).

\section{RESULTS}

In the free-dropping test, very significant differences were found between varieties $(p=0.0039)$ (table 1$)$. The variety with the highest percentage of damage was 'Marisol' overripe, and the variety with the lowest percentage of damage was 'Valencia Late.' Previous temperature and relative humidity were not found to have any significant effect on the percentage of fruit damage $(p=0.6684$ and $\mathrm{p}=0.4946$, respectively).

In the peel puncture resistance test, analysis of variance showed highly significant effects $(\mathrm{p}<0.001)$ of variety and relative humidity during the previous $48 \mathrm{~h}$ on the maximum
Table 2. Three-way analysis of variance of peel puncture deformation (maximum deformation in the force deformation curve) and wholefruit resistance to compression (maximum force deformation ratio in the compression force deformation curve) according to variety, temperature $48 \mathrm{~h}$ prior to testing (Temp), and relative humidity $48 \mathrm{~h}$ prior to testing (RH) (99\% confidence interval).

\begin{tabular}{|c|c|c|c|c|}
\hline \multirow[b]{2}{*}{ Source } & \multicolumn{2}{|c|}{$\begin{array}{c}\text { Maximum Puncture } \\
\text { Deformation } \\
(\mathrm{mm})\end{array}$} & \multicolumn{2}{|c|}{$\begin{array}{c}\text { Compression } \\
\text { Resistance } \\
\left(\mathrm{N} \mathrm{mm}^{-1}\right) \\
\end{array}$} \\
\hline & F-ratio & p-Value & F-ratio & p-Value \\
\hline Variety & 411.63 & 0.0000 & 746.38 & 0.0000 \\
\hline Temp & 2.54 & 0.1126 & 42.83 & 0.0000 \\
\hline $\mathrm{RH}$ & 169.11 & 0.0000 & 20.29 & 0.0000 \\
\hline \multicolumn{5}{|l|}{ Interactions } \\
\hline Variety $\times$ Temp & 3.17 & 0.0145 & 10.55 & 0.0000 \\
\hline Variety × RH & 24.64 & 0.0000 & 2.22 & 0.0676 \\
\hline Temp $\times$ RH & 3.61 & 0.0586 & 2.26 & 0.1339 \\
\hline Variety $\times$ Temp $\times \mathrm{RH}$ & 2.28 & 0.0615 & 0.20 & 0.9361 \\
\hline
\end{tabular}

puncture deformation (mm) (table 2). The effect of temperature on puncture resistance was not significant, but temperature had a highly significant effect on compression resistance. The temperature conditions over the previous $48 \mathrm{~h}$ had a higher effect on whole-fruit resistance than on peel resistance. However, the relative humidity conditions over the previous $48 \mathrm{~h}$ had a strong effect on both peel and whole-fruit resistance. An interaction effect of two factors is also evident, i.e., variety $\times$ temperature and variety $\times$ relative humidity. The storage conditions have a different effect depending on the variety (table 3 ).

In the puncture test, all the varieties showed highly significant differences in peel puncture deformation (mm) (tables 1 and 2). Significant differences were found for 'Valencia Late' and 'Marisol' peel puncture deformation at different stages of ripeness. The average maximum puncture deformation for 'Valencia Late' was $1.50 \mathrm{~mm}$, compared to $4.03 \mathrm{~mm}$ for 'Valencia Late' overripe. The average maximum puncture deformation for 'Marisol' was $1.81 \mathrm{~mm}$, compared to $5.93 \mathrm{~mm}$ for 'Marisol' overripe. This increment in puncture deformation is due to the softening of the peel in the overripe fruits. The variety with the lowest peel puncture deformation was 'Valencia Late,' and the variety with the highest peel puncture deformation was 'Marisol' overripe.

The variety with the significantly highest damage percentage ('Marisol' overripe) was also the variety with the significantly highest peel puncture deformation, thereby indicating the lowest resistance to peel puncture. In the same way, the variety with the significantly lowest damage

Table 3. Maximum puncture deformation and compression resistance according to variety, environmental (Env) or refrigerated (Refr) temperature, and high ( $80 \%$ to $95 \%)$ or medium $(50 \%$ to $80 \%)$ relative humidity. ${ }^{\text {[a] }}$

\begin{tabular}{|c|c|c|c|c|c|c|c|c|c|c|}
\hline \multirow{4}{*}{$\frac{\text { Variety }}{\text { 'Valencia Late' }}$} & \multicolumn{5}{|c|}{ Maximum Puncture Deformation (mm) } & \multicolumn{5}{|c|}{ Compression Resistance $\left(\mathrm{N} \mathrm{mm}^{-1}\right)$} \\
\hline & \multirow{3}{*}{$\begin{array}{l}\text { Variety } \\
1.50 \mathrm{a}\end{array}$} & \multicolumn{2}{|c|}{ Temperature } & \multicolumn{2}{|c|}{ Relative Humidity } & \multirow{3}{*}{$\begin{array}{l}\text { Variety } \\
6.09 \text { a }\end{array}$} & \multicolumn{2}{|c|}{ Temperature } & \multicolumn{2}{|c|}{ Relative Humidity } \\
\hline & & Env & $1.54 \mathrm{a}$ & High & $1.33 \mathrm{a}$ & & Env & $5.82 \mathrm{a}$ & High & $6.08 \mathrm{a}$ \\
\hline & & Refr & $1.47 \mathrm{a}$ & Medium & $1.68 \mathrm{a}$ & & Refr & $6.37 \mathrm{~b}$ & Medium & $6.11 \mathrm{a}$ \\
\hline \multirow{2}{*}{$\begin{array}{c}\text { 'Valencia Late' } \\
\text { overripe }\end{array}$} & \multirow{2}{*}{$1.81 \mathrm{~b}$} & Env & $1.74 \mathrm{a}$ & High & $1.58 \mathrm{a}$ & \multirow{2}{*}{$5.45 \mathrm{~b}$} & Env & $4.98 \mathrm{a}$ & High & $5.57 \mathrm{a}$ \\
\hline & & Refr & $1.87 \mathrm{a}$ & Medium & $2.03 \mathrm{~b}$ & & Refr & $5.92 \mathrm{~b}$ & Medium & $5.33 \mathrm{~b}$ \\
\hline \multirow{2}{*}{ 'Marisol' } & \multirow{2}{*}{$4.03 \mathrm{c}$} & Env & $4.15 \mathrm{a}$ & High & $3.62 \mathrm{a}$ & \multirow{2}{*}{$3.75 \mathrm{c}$} & Env & $3.46 \mathrm{a}$ & High & $3.89 \mathrm{a}$ \\
\hline & & Refr & $3.91 \mathrm{a}$ & Medium & $4.44 \mathrm{~b}$ & & Refr & $4.03 \mathrm{~b}$ & Medium & $3.60 \mathrm{~b}$ \\
\hline \multirow{2}{*}{ 'Orogrande' } & \multirow{2}{*}{$3.28 \mathrm{~d}$} & Env & $3.19 \mathrm{a}$ & High & $2.87 \mathrm{a}$ & \multirow{2}{*}{$2.51 \mathrm{~d}$} & Env & $2.57 \mathrm{a}$ & High & $2.34 \mathrm{a}$ \\
\hline & & Refr & $3.37 \mathrm{a}$ & Medium & 3.69 a & & Refr & $2.45 \mathrm{a}$ & Medium & $2.67 \mathrm{a}$ \\
\hline 'Marisol' & \multirow{2}{*}{$5.93 \mathrm{e}$} & Env & $6.24 \mathrm{a}$ & High & $4.63 \mathrm{a}$ & \multirow{2}{*}{$1.75 \mathrm{e}$} & Env & $1.71 \mathrm{a}$ & High & $2.03 \mathrm{a}$ \\
\hline overripe & & Refr & $5.62 \mathrm{a}$ & Medium & $7.23 \mathrm{~b}$ & & Refr & $1.79 \mathrm{a}$ & Medium & $1.48 \mathrm{~b}$ \\
\hline
\end{tabular}

a] Within a column, means followed by the same letter are not significantly different at the $95 \%$ confidence level (according to the Duncan test). 
percentage ('Valencia Late') was also the variety with the significantly lowest peel puncture deformation. The effect of temperature on puncture resistance was not significant (table 2). High relative humidity prior to mechanical handling reduced peel puncture deformation, thereby increasing resistance to peel puncture (fig. 2).

In the whole-fruit compression resistance test, the analysis of variance showed a highly significant effect ( $\mathrm{p}<$ 0.001) of the three experimental factors: variety, temperature $48 \mathrm{~h}$ before testing, and relative humidity $48 \mathrm{~h}$ before testing (table 2). An interaction effect of two factors (variety and temperature) was also evident. Temperature did not affect compression resistance in the same way for all the varieties (table 3 ).

In the compression test, all the varieties showed significant differences in whole-fruit compression resistance $\left(\mathrm{N} \mathrm{mm}^{-1}\right)$ (table 1). Significant differences in compression resistance were found for 'Valencia Late' and 'Marisol' with different stages of ripeness.

The variety with the significantly highest damage percentage ('Marisol' overripe, with a damage percentage of $22.5 \%$ ) was also the variety with the significantly lowest compression resistance $\left(1.75 \mathrm{~N} \mathrm{~mm}^{-1}\right)$. In the same way, the variety with the significantly lowest damage percentage ('Valencia Late,' with a damage percentage of $0.0 \%$ ) was also the variety with the significantly highest compression resistance $\left(6.10 \mathrm{~N} \mathrm{~mm}^{-1}\right)$.

Refrigerated temperature prior to mechanical handling increased whole-fruit compression resistance in 'Marisol,' 'Valencia Late,' and 'Valencia Late' overripe (table 3). For 'Marisol' and 'Valencia Late,' refrigerated temperature increased the compression resistance independently of the relative humidity conditions (fig. 3). High relative humidity prior to mechanical handling produced a significant increase in whole-fruit compression resistance (table 3). However, the effect of relative humidity differed depending on the variety (fig. 3).

\section{DisCUSSION AND CONCLUSIONS}

Citrus impact damage, measured as a percentage of damaged fruit in the dropping test, depended significantly on the variety. 'Marisol' overripe was the variety with the highest damage percentage, and 'Valencia Late' was the variety with the lowest damage percentage. These results confirm those found by Menesatti et al. (2005) and Ortiz et al. (2011), which showed that citrus damage susceptibility depended on variety and the stage of ripeness.

Mechanical properties, i.e., peel puncture deformation $(\mathrm{mm})$ and whole-fruit compression resistance $\left(\mathrm{N} \mathrm{mm}^{-1}\right)$, depended on the variety and on the previous storage conditions. Refrigerated temperature $\left(4^{\circ} \mathrm{C}\right.$ to $\left.8^{\circ} \mathrm{C}\right)$ and high relative humidity ( $80 \%$ to $95 \%$ ) prior to mechanical handling significantly increased whole-fruit compression resistance. Peel puncture deformation was significantly influenced by storage humidity. High relative humidity ( $80 \%$ to $95 \%)$

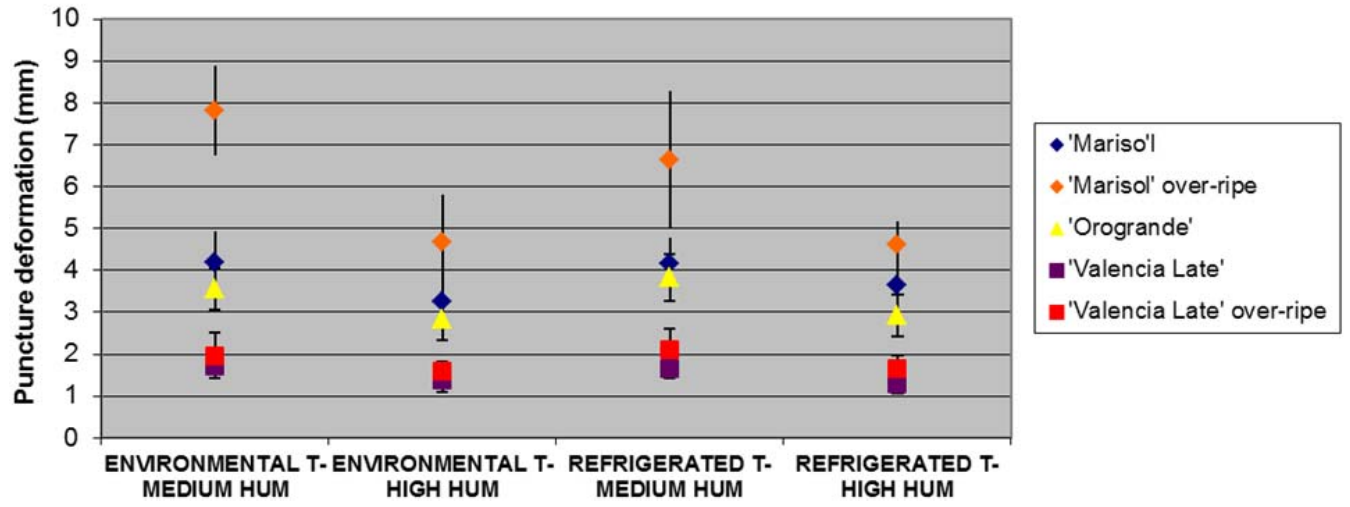

Figure 2. Maximum puncture deformation ( $\mathrm{mm}$ ) for the varieties according to temperature (environmental and refrigerated) and relative humidity (medium and high).

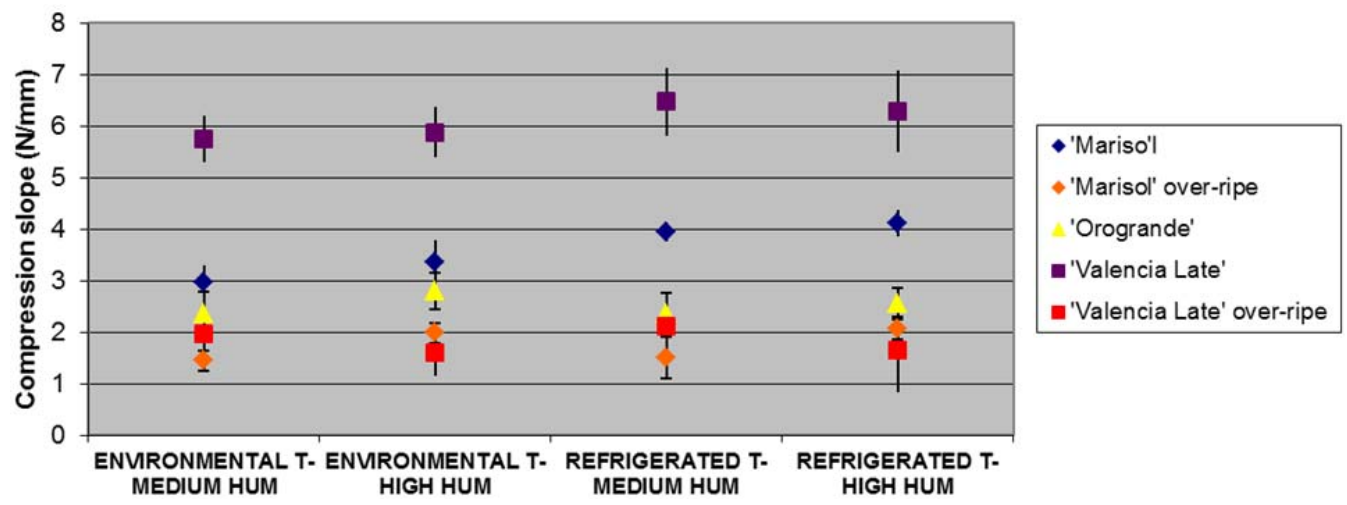

Figure 3. Compression resistance (slope from the force deformation compression curve, $\mathrm{N} \mathrm{mm}^{-1}$ ) for the varieties according to temperature (environmental and refrigerated) and relative humidity (medium and high). 
reduced peel puncture deformation compared to medium relative humidity (50\% to $80 \%$ ), thereby increasing peel puncture resistance. As García et al. (1995) maintained, peel puncture deformation is the physical parameter that is most closely related to fruit turgidity, and it is influenced by storage humidity.

A low temperature $\left(4^{\circ} \mathrm{C}\right.$ to $\left.8^{\circ} \mathrm{C}\right)$ over the previous $48 \mathrm{~h}$ compared to environmental conditions $\left(16^{\circ} \mathrm{C}\right.$ to $\left.25^{\circ} \mathrm{C}\right)$ increased whole-fruit compression resistance. High humidity (80\% to $95 \%$ ) over the previous $48 \mathrm{~h}$ compared to medium relative humidity (50\% to $80 \%$ ) increased both peel puncture resistance and whole-fruit compression resistance. Recommended citrus fruit storage conditions are therefore $90 \%$ relative humidity and $4^{\circ} \mathrm{C}$ to $10^{\circ} \mathrm{C}$ for mandarins and $2^{\circ} \mathrm{C}$ to $5^{\circ} \mathrm{C}$ for oranges. A storage period of $48 \mathrm{~h}$ will increase citrus fruit peel puncture resistance as well as wholefruit resistance to compression.

Because of the different properties of the citrus varieties, some of them could be more resistant to mechanical handling. Citrus varieties such as 'Valencia Late,' with high compression resistance and low peel deformation, could be apt for aggressive mechanical handling, given suitable previous temperature and relative humidity conditions.

Fruit damage susceptibility measured as a free fall from a height of $2 \mathrm{~m}$ was not related to storage temperature and humidity, and no clear relationship between dynamic impact damage and physical properties was proved. However, the physical properties tested could be related to other damage caused during harvest and postharvest handling, i.e., whole-fruit compression resistance could be related to damage due to static compression forces, and puncture resistance could be related to damage cause by puncturing and abrasion.

\section{ACKNOWLEDGEMENTS}

This study was funded by the Ministerio de Ciencia e Innovación (research project RTA2009-00118-C02-02) and FEDER.

\section{REFERENCES}

Arazuri, S., Jarén, C., Arana, J. I., \& Pérez de Ciriza, J. J. (2007). Influence of mechanical harvest on the physical properties of processing tomato (Lycopersicon esculentum Mill.). J. Food Eng., 80(1), 190-198.

Armstrong, P. A., Timm, E. J., \& Schulte, N. L. (1991). Apple bruising in bulk bins during road transport. ASAE Paper No. 911020. St. Joseph, Mich.: ASAE.

Bielza, C., Barreiro, P., Rodriguez-Galiano, M. I., \& Martín, J. (2003). Logistic regression for simulating damage occurrence on a fruit grading line. Comput. Electr. Agric., 39(2), 95-113.

Blasco, J., Aleixos, N., Gómez, J., \& Moltó, E. (2007). Citrus sorting by identification of the most common defects using multispectral computer vision. J. Food Eng., 83(3), 384-393.

Bollen, A. F., Cox, N. R., Dela Rue, B. T., \& Painter, D. J. (2001). A descriptor for damage susceptibility of a population of produce. J. Agric. Eng. Res., 78(4), 391-395.

Churchill, D. B., Summer, H. R., \& Whitney, J. D. (1980). Peel strength properties of three orange varieties. Trans. ASAE, 23(1), 173-176.

Ericsson, N. A., \& Tahir, I. I. (1996). Studies on apple bruising: I.
Estimation of incidence and susceptibility differences in the bruising of three apple cultivars. Acta Agric. Scandinavica B, 46(4), 209-213.

Flood, S. J., Burks, T. F., \& Texeira, A. A. (2006). Physical properties of oranges in response to applied gripping forces for robotic harvesting. Trans. ASAE, 49(2), 341-346. http://dx.doi.org/10.13031/2013.20402.

García, J. L., Ruiz-Altisent, M., \& Barreiro, P. (1995). Factors influencing mechanical properties and bruise susceptibility of apples and pears. J. Agric. Eng. Res., 61(1), 11-18. http://dx.doi.org/10.1006/jaer.1995.1025.

García-Ramos, F. J., Ortiz-Cañavate, J., \& Ruiz-Altisent, M. (2004). Evaluation and correction of the mechanical aggressiveness of commercial sizers used in stone fruit packing lines. J. Food Eng., 63(2), 171-176. http://dx.doi.org/10.1016/S0260-8774(03)00297-8.

Hertog, M. L., Ben-Arie, R., Róth, E., \& Nicolai, B. M. (2004). Humidity and temperature effects on invasive and non-invasive firmness measures. Postharvest Biol. Tech., 33(1), 79-91. http://dx.doi.org/10.1016/j.postharvbio.2004.01.005.

Juste, F., Gracia, C., Molto, E., Ibañez, R., \& Castillo, S. (1988). Fruit bearing zones and physical properties of citrus for mechanical harvesting. In R. Goren, K. Mendel, \& N. Goren (Eds.), Proc. 6th Intl. Citrus Congress (pp. 1801-1809). Rehovot, Israel: Balaban.

Kader, A. A. (2005). Increasing food availability by reducing postharvest losses of fresh produce. ISHS Acta Hort. 682: 21692176. Retrieved from www.actahort.org/books/682/682_296.htm.

Lin, T., \& Pitt, R. E. (1986). Rheology of apple and potato tissue as affected by cell turgor pressure. J. Texture Studies, 17(3), 291313. http://dx.doi.org/10.1111/j.1745-4603.1986.tb00554.x.

Lu, L. X., \& Wang, Z. W. (2007). Dropping bruise fragility and bruise boundary of apple fruit. Trans ASABE, 50(4), 1323-1329. http://dx.doi.org/10.13031/2013.23609.

Menesatti, P., Paglia, G., Solaini, S., Niciarelli, I., \& D’Andrea, S. (2005). Mechanical damage to citrus fruit. Informatore Agrari, 61(2), 53-55.

Mohsenin, N. N. (1986). Physical Properties of Plant and Animal Materials. New York, N.Y.: Gordon and Breach Science.

Ortiz, C., Blasco, J., Balasch, S., \& Torregrosa, A. (2011). Shockabsorbing reception surfaces for collecting fruit during the mechanical harvesting of citrus. Biosystem Eng., 110(1), 2-9. http://dx.doi.org/10.1016/j.biosystemseng.2011.05.006.

Pang, D. W., Studman, C. J., Banks, N. H., \& Baas, P. H. (1996). Rapid assessment of the susceptibility of apples to bruising. $J$. Agric. Eng. Res., 64(1), 37-47. http://dx.doi.org/10.1006/jaer.1996.0044.

Scherrer Montero, C. R., Loss Schwarz, L., Cunha dos Santos, L., Salete Andreazza, C., Pereira Kechinski, C., \& Joao Bender, R. (2009). Postharvest mechanical damage affects fruit quality of 'Montenegrina' and 'Rainha' tangerines. Pesquisa Agropecuaria Brasileira, 44(12), 1636-1640. http://dx.doi.org/10.1590/S0100204X2009001200011.

Sigh, K. K., \& Reddy, B. S. (2006). Postharvest physicomechanical properties of orange peel and fruit. J. Food Eng., 73(2), 112-120. http://dx.doi.org/10.1016/j.jfoodeng.2005.01.010.

Timm, E. J., \& Guyer, D. E. (1998). Tart cherry firmness and quality changes during mechanical harvesting and handling. Appl. Eng. Agric., 4(2), 153-158.

http://dx.doi.org/10.13031/2013.19364.

Torregrosa, A., Ortí, E., Martín, B., Gil, J., \& Ortiz, C. (2009). Mechanical harvesting of oranges and mandarins in Spain. Biosyst. Eng., 104(1), 18-24. http://dx.doi.org/10.1016/j.biosystemseng.2009.06.005. 
Tuset, J. J. (1987). Podredumbres de los Frutos Cítricos. Valencia, Spain: Generalitat Valenciana.

Van Zeebroeck, M., Van Linden, V., Ramon, H., De Baerdemaeker, J., Nicolai, B. M., \& Tijskens, E. (2007). Impact damage of apples during transport and handling. Postharvest Biol. Tech., 45(2), 157-167. http://dx.doi.org/10.1016/j.postharvbio.2007.01.015.

Yahia, E. M., Barry-Ryan, C., \& Dris, R. (2004). Treatments and techniques to minimise the postharvest losses of perishable food crops. Production Practices and Quality Assessment of Food Crops, Vol. 4: 95-133. Dordrecht, The Netherlands: Springer. 